\title{
FUNGSI BAHASA PADA KAOS DI KALANGAN REMAJA
}

\author{
Markub \\ FKIP Universitas Islam Darul Ulum Lamongan \\ maskub@unisda.ac.id
}

\begin{abstract}
Language as a communication tool plays a very important role in human life because human language can interact and talk about anything. Language as a tool to convey thoughts, ideas, concepts, or feelings. An intellectual must think and the process of thinking definitely requires language. Language also functions as a means for social interaction and the media conveys ideas, the purpose of this study is to describe the function of language in counsels among adolescents. The method used in this study is a qualitative descriptive method. The data in this study are various languages including the form of language, language functions, and the meaning of expressions. The form of language in the form of words, phrases, clauses, and sentences. Language functions in the form of expression functions, information functions, exploration functions, persuasion functions, entertainment functions, Data sources in this study are the function of language on shirts among teenagers. The technique used in this data collection is documentation, see, and note. The results of research on the function of shirts on teenagers that the function of language is a tool of social interaction, as a medium for conveying ideas, concepts, thoughts, and expressions of feelings including expression functions, information functions, exploration functions, persuasion functions, and entertainment functions on shirts. among teenagers.
\end{abstract}

Keyword: Language functions, $t$-shirts

Abstrak: Bahasa sebagai alat komunikasi memegang peranan yang sangat penting dalam kehidupan manusia karena dengan bahasa manusia dapat berinteraksi dan berbicara mengenai apa saja. Bahasa sebagai alat menyampaikan pikiran, gagasan, konsep, ataupun perasaan. Seorang intelektual pasti berpikir dan proses berpikir pasti memerlukan bahasa. Bahasa juga berfungsi sebagai sarana untuk interaksi sosial dan media menyampaikan gagasan, tujuan penelitian ini mendeskripsikan fngsi bahasa pada koas di kalangan remaja, Metode yang digunakan dalam penelitian ini adalah metode deskriptif kualitatif. Data dalam penelitian ini adalah ragam bahasa meliputi bentuk bahasa, fungsi bahasa, dan makna ungkapan. Bentuk bahasa yang berupa kata, frasa, klausa, dan kalimat. Fungsi bahasa berupa fungsi ekspresi, fungsi informasi, fungsi eksplorasi, fungsi persuasi, fungsi entertainment, Sumber data dalam penelitian ini adalah Fungsi bahasa pada kaos di kalangan remaja. Teknik yang digunakan dalam pengumpulan data ini adalah dokumentasi, simak, dan catat. Hasil penelitian Fungsi bajasa pada kaos di kalangan remaja bahwa Fungsi bahasa merupakan alat interaksi sosial, sebagai media untuk menyampaikan sebuah gagasan, konsep, pikiran, dan ungkapan suatu perasaan meliputi fungsi ekspresi, fungsi informasi, fungsi eksplorasi, fungsi persuasi, dan fungsi entertaiment pada kaos di kalangan remaja.

Kata kunci: Fungsi bahasa, kaos . 


\section{PENDAHULUAN}

Bahasa sebagai alat komunikasi memegang peranan yang sangat penting dalam kehidupan manusia karena dengan bahasa manusia dapat berinteraksi dan berbicara mengenai apa saja. Bahasa sebagai alat menyampaikan pikiran, gagasan, konsep, ataupun perasaan. Dalam ilmu dan teknologi bahasa berfungsi sebagai sarana untuk berkomunikasi.

Bahasa merupakan sistem komunikasi yang mempergunakan simbol-simbol vokal (bunyi ujaran) yang bersifat arbitrer, yang dapat diperkuat dengan gerak-gerik badaniah yang nyata (Keraf, 1997:2). Sementara itu, menurut Keraf (1984:16) mengatakan bahwa bahasa sebagai alat komunikasi antar anggota masyarakat terdiri dari dua bagian yang besar yaitu bentuk (arus ujaran) dan makna (isi).

Fungsi bahasa bagi setiap orang ada empat hal yaitu: (1) untuk menyatakan ekspresi diri, (2) sebagai alat komunikasi, (3) sebagai alat untuk mengadakan integrasi dan adaptasi sosial, (4) sebagai alat kontrol sosial (Keraf, 1997:3).

Kalau kita cermati, sebenarnya ada satu lagi fungsi bahasa yang selama ini kurang disadari oleh anggota masyarakat, yaitu sebagai alat untuk berpikir. Seperti kita ketahui, ilmu tentang cara berpikir adalah logika. Dalam proses berpikir adalah logika. Dalam proses berpikir, bahasa selalu hadir bersama logika untuk merumuskan konsep, preposisi dan simpulan. Segala penghitungan yang menyangkut perhitungan atau kalkulasi pembahasan atau analisis, bahkan berangan-angan atau berhayal, hanya dimungkinkan berlangsung melalui proses berpikir disertai alatnya yang tidak lain adalah bahasa .

Sejalan dengan uraian di atas dapat diformalisasikan bahwa semakin tinggi kemampuan berbahasa seseorang, semakin tinggi pula kemampuan pola berpikirnya. Dengan berpegangan pada formula itulah di dalam prakata buku ini penulis berani mengatakan seseorang tidak mungkin menjadi intelektual tanpa menguasai bahasa. Seorang intelektual pasti berpikir dan proses berpikir pasti memerlukan bahasa. Bahasa yang diperlukan memiliki banyak ragam.

Fungsi bahasa yang digunakan di kaos itu sendiri Fungsi bahasa adalah suatu komunikasi yang diadakan dengan mempergunakan bunyi yang dihasilkan oleh ucap manusia yang berbentuk isyarat tulis yang ada pada kaos. Sementara itu, makna ungkapan adalah isi yang dapat menimbulkan reaksi atau tanggapan orang lain dan terkandung di dalam tulisan yang ada pada kaos. Berdasarkan latar belakang yang sudah dipaparkan maka penelitian ini mendiskpsikan fungsi bahasa pada kaos di kalangan remaja.

\section{Landasan Teori Bahasa}

Bahasa sebagai alat komunikasi memegang peranan yang sangat penting dalam kehidupan manusia karena dengan bahasa manusia dapat berinteraksi dan berbicara mengenai apa saja. Bahasa sebagai alat menyampaikan pikiran, gagasan, konsep, ataupun perasaan. Dalam ilmu dan teknologi bahasa berfungsi sebagai sarana untuk berkomunikasi. Bahasa merupakan sistem komunikasi yang mempergunakan simbol-simbol vokal (bunyi ujaran) yang bersifat arbitrer, yang dapat diperkuat dengan gerak-gerik badaniah yang nyata (Keraf, 1997:2). Pendapat lain dikemukakan oleh Keraf (1984:16) mengatakan bahwa bahasa sebagai alat komunikasi antar anggota masyarakat terdiri dari dua bagian yang besar yaitu bentuk (arus ujaran) dan makna (isi).

Menurut Kridalaksana (dalam Aminuddin, 2001:28) mengatakan bahwa Bahasa adalah sistem lambang arbitrer yang dipergunakan suatu masyarakat 
untuk bekerja sama, berinteraksi, dan mengidentifikasi diri. Beberapa hal menarik yang dapat disimpulkan dari batasan pengertian itu adalah (a) bahasa merupakan suatu sistem, (b) sebagai sistem, bahasa bersifat arbitrer, dan (c) sebagai sistem arbitrer, bahasa dapat digunakan untuk berinteraksi, baik dengan orang lain maupun dengan diri sendiri.

Sebagai sistem, bahasa memiliki komponen-komponen yang tersusun secara hierarkis. Komponen itu meliputi komponen fonologos, morfologis, sintaksis, dan semantis. Sesuai dengan keberadaannya sebagai suatu sistem, masing-masing komponen tersebut saling memberi arti, saling berhubungan, dan saling menentukan. Pada sisi lain setiap komponen juga memiliki sistemnya sendiri. Sistem pada tataran bunyi, misalnya dikaji bidang fonologi, pada tataran kata dikaji bidang morfologi, dan kajian sistem pada tataran kalimat menjadi wilayah sintaksis. Sebagai subsistem, masing-masing komponen tersebut juga telah mengandung aspek semantis tertentu sehingga secara potensial dapat disusun dan kombinasikan untuk digunakan dalam komunikasi. Sistem yang mengatur hubungan makna dalam lambang kebahasaan maupun hubungan makna dalam lambang dengan dunia luar bahasa menjadi bidang kajian semantik.

Fungsi Bahasa

Secara umum bahasa mempunyai fungsi sebagai alat berinteraksi atau alat untuk komunikasi. Bahasa sebagai alat komunikasi antara pembaca atau penulis dengan pendengar atau pembaca. Menurut Sudaryanto (dalam Aslinda, 2007:89) dalam arti paling sederhana, kata "fungsi" dapat dipandang kata "penggunaan". Dalam komunikasi, bahasa berfungsi sebagai atau media untuk mengungkapkan gagasan, pikiran, konsep, atau perasaan pembicara. Apa yang dipikir, apa yang digagas, atau apa yang dirasa pembicara disampaikan melalui media bahasa. Para ahli merumuskan fungsi bahasa bagi setiap orang ada empat hal yaitu: (1) untuk menyatakan ekspresi diri, (2) sebagai alat komunikasi, (3) sebagai alat untuk mengadakan integrasi dan adaptasi sosial, (4) sebagai alat kontrol sosial (Keraf, 1997:3).

Dari sisi lain, menurut Kridalaksana (dalam Aslinda, 2007:89), kata fungsi mengacu pada beberapa pengertian, yaitu: (1) Beban makna suatu satuan bahasa, (2) Hubungan satu satuan dengan unsur-unsur gramatikal, leksikal, atau fonologi dalam suatu deret satuan, (3) Penggunaan bahasa untuk tujuan tertentu, (4) Peran unsur dalam satu ujaran dan hubungannya secara struktur dengan unsur lain, (5) Peran sebuah unsur dalam satuan sintaksis yang lebih luas, misalnya nomina yang berfungsi sebagai subjek atau objek.

Menurut Keraf

(1984:17) menyatakan bahwa komunikasi dengan mempergunakan bahasa itu adalah seumum-umumnya. Bila fungsi yang umum tadi kita perinci, maka kita dapat mengatakan bahwa bahasa mempunyai fungsi sebagai berikut (1) Untuk tujuan praktis yaitu untuk mengadakan antar hubungan dalam pergaulan sehari-hari. (2) Untuk tujuan artistik, dimana manusia mengolah dan mempergunakan bahasa itu dengan cara seindah-indahnya guna pemuasan rasa estetis manusia. (3) Menjadi kunci mempelajari pengetahuanpengetahuan lain. (4) Tujuan filologis: untuk mempelajari naskah-naskah tua untuk menyelidiki latar belakang sejarah manusia, sejarah kebudayaan dan adat istiadat, serta perkembangan bahasa itu sendiri.

Perincian fungsi-fungsi bahasa sebagai telah disebut di atas merupakan fungsi yang umum bagi bahasa mana saja. Namun setiap bahasa dapat 
mengkhususkan fungsinya sesuai dengan kepentingan nasional sari suatu bangsa (Keraf, 1984:17). Fungsi bahasa itu adalah alat interaksi sosial, dalam arti alat untuk menyampaikan pikiran, gagasan, konsep, atau jaga perasaan. Dalam hal ini, Wardhaugh (dalam Chaer, 2009:33) seorang pakar sosiolinguistik juga mengatakan bahwa fungsi bahasa adalah alat komunikasi manusia, baik lisan maupun tulisan. Namun, fungsi ini sudah mencakup lima fungsi dasar yang menurut Kinneavy disebut fungsi ekspresi, fungsi informal, fungsi eksplorasi, fungsi persuasi, dan fungsi entertainmen (Michel dalam Chaer, 2009:33).

Kelima fungsi dasar ini mewadahi konsep bahwa bahasa alat untuk melahirkan ungkapan-ungkapan batin yang ingin disampaikan seorang penutur kepada orang lain. Pernyataan senang, benci, kagum, marah, tingkah laku, gerak gerik, dan mimik juga berperan dalam pengungkapan ekspresi batin itu. Fungsi informasi adalah fungsi untuk menyampaikan pesan atau amanat kepada orang lain. Fungsi eksplorasi adalah penggunaan bahasa untuk menjelaskan suatu hal, perkara, dan keadaan. Fungsi persuasi adalah penggunaan bahasa yang bersifat mempengaruhi atau mengajak orang lain untuk melakukan atau tidak melakukan sesuatu secara baik-baik. Yang terakhir fungsi entertaimen adalah penggunaan bahasa dengan maksud menghibur,menyenangkan, atau memuaskan perasaan hati.

Dengan bahasa manusia dapat menyatukan kegembiraan, kesedihan, harapan, permohonan, ajakan, kritikan, dan perintah. Fungsi bahasa menurut Hillday dalam Sumarlan, 2003 : 1-2) meliputi (a) Fungsi instrumental, yakni bahasa berfungsi menghasilkan kondisikondisi tertentu dan menyebabkan terjadinya peristiwa. Fungsi ini berhubungan dengan imperatif, yaitu mengandung tindakan-tindakan komunikatif yang menghasilkan kondisikondisi tertentu. Fungsi ini berkaitan dengan menyatakan ajakan, mengkritik, menyatakan larangan, dan mengingatkan. (b) Fungsi regulatif, yaitu sebagai pengawas, pengendali atau mengatur peristiwa, atau untuk mengendalikan orang lain. Fungsi ini berkaitan dengan fungsi yang menyatakan larangan, mengingatkan, dan mengkritik. (c) Fungsi pameran, yaitu untuk membuat pertanyaan-pertanyaan, menyampaikan fakta, menjelaskan atau melaporkan realitas sebenarnya sebagaimana yang dilihat dan dialami. Yang termasuk fungsi ini yaitu mempertanyakan sesuatu, memberikan informasi, dan menyindir. (d) Fungsi interaksi, yaitu fungsi menjamin dan memantapkan ketahanan dan keberlangsungan komunikasi serta menjalin interaksi sosial. Fungsi ini berkaitan dengan fungsi menyatakan ajakan, memberi dukungan, mempertanyakan, permohonan, memberi informasi, dan menyindir. (d) Fungsi perseorangan, yaitu memberi kesempatan kepada pembaca untuk mengekspresikan perasaan, emosi pribadi, dan reaksi-reaksi yang mendalam. Yang termasuk fungsi ini adalah mempertanyakan, menyatakan, ajakan, memberi dukungan, mengkritik, menyatakan permohonan, mengungkapkan perasaan, atau sikap, mendoakan, menyindir, mengucapkan terima kasih, mengucapkan selamat, menawarkan sesuatu, dan mengingatkan.

Karena bahasa ini digunakan manusia dalam segala tindak kehidupan, sedangkan perilaku dalam kehidupan itu sangat luas dan beragam, maka fungsifungsi bahasa itu bisa menjadi sangat banyak sesuai dengan banyaknya tindak dan perilaku serta keperluan manusia dalam kehidupan. Oleh karena itu, dalam berbagai kepustakaan kita mungkin akan menemukan rincian fungsi-fungsi bahasa 
yang berbeda, beragam, dan berungkapan.

\section{Fungsi Bahasa dalam Kaos}

Fungsi dari bahasa pada umumnya yaitu: sebagi alat komunikasi atau alat perhubungan antar anggota-anggota masyarakat; suatu komunikasi yang diadakan dengan mempergunakan bunyi yang dihasilkan oleh alat ucap manusia. Komunikasi (Keraf, 1984:17). Para pakar linguistik desktiptif hampir sebagian besar memaparkan bahwa bahasa itu sebagai "satu sistem lambang atau simbol bunyi yang memiliki sifat arbitrer" yang biasanya ditambah dengan "yang $d i$ gunakan atas sekelompok anggota di masyarakat guna berinteraksi dan mengidentifikasikan diri" (Chaer, 1994). Terdapat juga bagian sentral di dalam pengertian di atas yang menyatakan tentang hakikat dari suatu bahasa dan juga bagian tambahan yang mengatakan apa saja fungsi dari suatu bahasa tersebut.

Salah satu fungsi dari bahasa dalam segi yang mendasar ialah bahwa bahasa itu merupakan alat interaksi sosial, sebagai media untuk menyampaikan sebuah gagasan, konsep, pikiran, dan ungkapan suatu perasaan. Tetapi, fungsi ini telah mencakup kelima fungsi dasar dari ahli sebelumnya (Kinneavy) yang menyatakan lima fungsi bahasa tersebut yaitu fungsi ekspresi, fungsi informasi, fungsi eksplorasi, fungsi persuasi, dan fungsi entertaiment. Berikut kelima fungsi dasar dari bahasa itu dikemukakan oleh Chaer (2014:15) Kelima fungsi ini merupakan wadah sebuah bahasa sebagai alat untuk melahirkan ungkapanungkapan dari batin seorang penutur kepada orang lain yang dijelaskan sebagai berikut.

\section{Fungsi Ekspresi}

Perasaan senang, bahagia, cinta, benci, kagum, marah, kesal, sedih, dan kecewa itu semua bisa diungkapkan lewat bahasa dengan ditambahkan suatu ekspresi dari hati yang dapat berupa seperti mimik muka, gerak tubuh (mata, tangan, kaki, dan bagian tubuh lainnya), melalui Kaos yang bertuliskan "khayalan kematian" berperan sebagai pengungkapan ekspresi batin seseorang.

\section{Fungsi Informasi}

Fungsi bahasa ini sebagai penyampaian pesan atau amanat dari dalam atau luar hati seseorang kepada orang lain yang dituju. Dari Kaos yang bertuliskan "ingatlah kematian akan selalu membayangi hidupmu" memiliki fungsi yang menginformasikan kepada manusia agar selalu ingat kepada kematian dan lebih mendekatkan diri kepada Tuhan.

\section{Fungsi Eksplorasi}

Maksudnya ialah bahasa di sini berperan guna menjelaskan suatu hal, masalah, atau sebuah keadaan yang sedang atau sudah terjadi. Dalam Kaos yang bertuliskan "miskin di negeri yang kaya" hal ini menjelaskan keadaan yang terjadi di Indonesia.

\section{Fungsi Persuasi}

Bahasa yang dipergunakan memiliki sifat untuk memberi pengaruh atau mengajak orang lain untuk melakukan atau sebaliknya (dengan tidak melakukan) sesuatu hal dengan sebaiknya. Melalui Kaos yang bertuliskan "sholatlah sebelum disholatkan" gambaran untuk mengajak seseorang selalu beribadah.

\section{Fungsi Entertainment}

Disini bahasa memiliki peranan atau tujuan untuk memuaskan, menghibur, bahkan dapat menyenangkan suatu perasaan batin diri sendiri atau kepada orang lain. Melalui Kaos Bertuliskan "ternyata Google nggak mampu menemukan jodoh saya" hal ini menggambarkan suatu kekenyolan dan menghibur seseorang.

\section{METODE PENELITIAN}

Metode yang digunakan dalam penelitian ini adalah metode deskriptif 
kualitatif. Data dalam penelitian ini adalah ragam bahasa meliputi bentuk bahasa, fungsi bahasa, dan makna ungkapan. Bentuk bahasa yang berupa kata, frasa, klausa, dan kalimat. Fungsi bahasa berupa fungsi ekspresi, fungsi informasi, fungsi eksplorasi, fungsi persuasi, fungsi entertainment, Sumber data dalam penelitian ini adalah Fungsi bahasa pada kaos di kalangan remaja. Teknik yang digunakan dalam pengumpulan data ini adalah dokumentasi, simak, dan catat.

\section{PEMBAHASAN}

Fungsi dari bahasa dalam segi yang mendasar ialah bahwa bahasa itu merupakan alat interaksi sosial, sebagai media untuk menyampaikan sebuah gagasan, konsep, pikiran, dan ungkapan suatu perasaan. Pada Kaos di Kalangan Remaja memiliki ragam fungsi masingmasing dijelaskan sebagai berikut.

\section{Fungsi Ekspresi}

Menurut Chaer (2014:15) Fungsi ekspresi adalan ekspresi perasaan senang, bahagia, cinta, benci, kagum, marah, kesal, sedih, dan kecewa itu semua bisa diungkapkan lewat bahasa dengan ditambahkan suatu ekspresi dari hati yang dapat berupa seperti mimik muka, gerak tubuh (mata, tangan, kaki, dan bagian tubuh lainnya). Pada Kaos di Kalangan Remaja ditemukan fungsi ekspresi dapat ditemukan data sebagai berikut.

\section{(1) ikhlas \\ (2) panik}

Berdasarkan data (1) maka Fungsi kata “ikhlas" merupakan sebagai ekspresi dari batin seseorang dalam merelakan sesuatu. Sedangkan pada data (2) termasuk fungsi kata "panik" memiliki fungsi ekspresi dari sesorang yang selalu gegabah dalam setiap hal.

\section{Fungsi Informasi}

Fungsi Informasi Menurut Chaer (2014:15) adalah Fungsi bahasa sebagai penyampaian pesan atau amanat dari dalam atau luar hati seseorang kepada orang lain yang dituju. Pada Kaos di Kalangan Remaja ditemukan fungsi bahasa sebagai berikut.

(3) ingatlah kematian akan selalu membayangi hidupmu

(4) siapa yang tidak berani mengambil keputusan tidak akan bisa melangkah maju

(5) jangan salahkan takdir, salahkan diri yang tak bisa merubah takdir

(6) kita bisa seperti ini karena kita yakin

(7) semua dimulai dari diri sendiri

(8) kenapa banyak orang bodoh, melihat orang hanya dari luar saja

(9) jika uang ini berkata 'kalian bodoh telah menuhankan aku

Pada data (3) menurut Chaer (2014:15) bahwa data tersebut memberikan informasi kepada manusia agar selalu ingat kepada kematian karena kematian akan datang sewaktu-waktu karena semua takdir ada di tangan tuhan. Pada (4) menginformasikan kepada pembaca untuk mencapai kemajuan dibutuhkan kepercayaan diri dan keberanian yang tinggi.

Fungsi bahasa menurut Chaer (2014:15) pada data (5) menginformasikan bahwa seseorang untuk tidak pasrah kepada takdir tapi juga harus disertai dengan usaha. Pada data (6) menginformasikan kepada orang lain jika ingin bisa melakukan sesuatu harus disertai kepercayaan diri yang tinggi dan data (7) berfungsi menginformasikan untuk memulai segala sesuatu dari diri sendiri jangan menunggu orang lain

Fungsi bahasa pada Kaos di Kalangan Remaja pada data (8) menurut Chaer (2014:15) bahwa fungsi bahasa ini menginformasikan kepada sesorang agar tidak melihat seseorang dari penampilanya tapi lihatlah dari hatinya, dan pada data (9) mempunyai fungsi untuk menginformasikan kepada orang 
lain agar tidak terlena mencari uang karena uang bukan segalanya.

\section{Fungsi Eksplorasi}

Fungsi eksplorasi adalah bahasa di sini berperan guna menjelaskan suatu hal, masalah, atau sebuah keadaan yang sedang atau sudah terjadi. Pada Kaos di Kalangan Remaja ditemukan beberapa fungsi eksplorasi dijelaskan sebagai berikut.

(10) miskin di negeri yang kaya

(11) ratakan dengan tanah

(12) kibarkan Benderaku

Menurut Chaer (2014:15) fungsi bahasa pada (10) adalah menjelaskan keadaan suatu bangsa yang tidak bisa memberdayakan kekayaaan di negeri sendiri dan pada data (11) berfungsi menjelaskan keadaan rakyat yang rumahnya digusur sedangkan pada data (12) berfungsi menjelaskan kepada rakyat agar selalu menjunjung tinggi tanah airnya.

\section{Fungsi Persuasi}

Fungsi persuasi adalah Bahasa yang dipergunakan memiliki sifat untuk memberi pengaruh atau mengajak orang lain untuk melakukan atau sebaliknya (dengan tidak melakukan) sesuatu hal dengan sebaiknya. Melalui Kaos di Kalangan Remaja ditemukan ragam persuasi dijelaskan sebagai berikut.

(15) jihad

(16) sholatlah sebelum disholatka)

(17) taubat

( 18) fokus

Berdasarkan pendapat Chaer (2014:15) bahwa bahwa kata jihad, Sholatlah sebelum disholatkan, taubat dan fokus pada data (15), (16), (17) dan (18) merupakan fungsi bahasa persuasi karena pada data (15) dan (16) mengajak para pembaca untuk jangan melupakan sholat. Pada (17) mengajak para pembaca agar segera bertaubat sebelum terlambat sedangkan data (18) mengajak para pembaca untuk konsentrasi dalam setiap hal.

\section{Fungsi Entertainment}

Fungsi entertainmet adalah disini bahasa memiliki peranan atau tujuan untuk memuaskan, menghibur, bahkan dapat menyenangkan suatu perasaan batin diri sendiri atau kepada orang lain. Melalui Kaos di Kalangan Remaja ditemukan ragam entertainment pada data sebagai berikut.

(19) Ternyata Google Nggak Mampu Menemukan Jodoh Saya

Data (19) Berdasarkan pendapat Chaer (2014:15) bahwa fungsi bahasa tersebut merupakan fungsi entertainment yaitu menunjukkan suatu kekonyolan dan menghibur seseorang untuk tidak menjadikan google sebagai ajang pencarian jodoh.

\section{Simpulan}

Pada penelitian yang berjudul Fungsi Bahasa pada Kaos di Kalangan Remaja dapat disimpulkan bahwa fungsi bahasa merupakan alat interaksi sosial, sebagai media untuk menyampaikan sebuah gagasan, konsep, pikiran, dan ungkapan suatu perasaan. Pada penelitian ini fungsi bahasa meliputi fungsi ekspresi, fungsi informasi, fungsi eksplorasi, fungsi persuasi, dan fungsi entertaiment.

\section{DAFTAR PUSTAKA}

Aminuddin. 2001. Semantik: Pengantar Studi tentang Makna. Malang: Sinar Baru Algesindo.

Aslinda. 2007. Pengantar Sosiolinguistik. Bandung. Refika Aditama.

Chaer, Abdul, 2080. Hubungan Bahasa, Kebudayaan, dan Pemikiran Dewan Bahasa, Jilid 24 Jakarta; Rineka Cipta 
Chaer, Abdul dan Leone Agustina, 2014. Sosiolinguistik Perkenalan Awal, Jakarta; Rineka Cipta

Keraf, Gorys. 1984. Tata Bahasa Indonesia. Flores: Nusa Indah.
1997. Komposisi: Sebuah

Pengantar Kemahian Bahasa. Jakarta: Nusa Indah.

Sumarlan, 2012, Kajian berbagai Varasi Bahasa, Yogyakarta: Graha Ilmu. 